\title{
A journey of a thousand miles begins with a single step: Applying evidence-based medicine to answer clinical questions
}

\section{Peter Seah Keng Tok}

Tok PSK. A journey of a thousand miles begins with a single step: Applying evidence-based medicine to answer clinical questions. Malays Fam Physician. 2021;16(3);132. https://doi.org/10.51866/lte1336

\section{Keywords:}

Research, research design,

evidence-based medicine,

evidence-based practice

\section{Authors:}

Peter Tok Seah Keng

(Corresponding author)

MD (UI), MPH (UM)

Department of Social and Preventive

Medicine, Faculty of Medicine

University of Malaya, Malaysia

Email: petertok.crc@gmail.com

\section{Dear Editor-in-Chief,}

I read the editorial 'We need a research plan' with great interest. ${ }^{1}$ The author highlighted the importance of going beyond exploratory studies and outlined the subsequent stages of health intervention development, evaluation and implementation. Going through the full cycle of the 'research journey' is indeed rewarding (for both patients and researchers alike), and I wish to thank the author for his pearls of wisdom.

Taking a leaf out of the research framework proposed in the editorial piece, perhaps it might also be useful to explore (exploratory) why most research articles are exploratory in nature. In this regard, a cross-sectional study of specialists in Malaysian government hospitals ${ }^{2}$ that explores their attitudes towards, barriers to and facilitators for conducting research may offer some insights. Frequently mentioned barriers that may be relevant include lack of funds, red tape in obtaining approvals, and the inadequacy of research skills, training opportunities and guidance from mentors. More often than not, studies that are beyond exploratory involve interventional research that may be resourceintensive, subject to higher scrutiny by ethical review boards (aptly so) and require a certain level of expertise or technical know-how.

While stakeholders do their part in the planning and implementation of strategies to break these barriers, we should continue to remain inquisitive and take a step further whenever possible. For example, when we face clinical conundrums in the provision of patient care, the systematic approach to the acquisition, appraisal and application of existing research evidence should always be practised to guide healthcare decisions. Indeed, that is one of the popular definitions of evidence-based medicine (EBM). ${ }^{3}$ Evidence-based case reports also illustrate the process of how evidence can be applied at all stages of patient care. ${ }^{4}$ Additionally, when we apply EBM in our daily practice, we are essentially exploring and reviewing (exploratory) existing evidence pertaining to the clinical questions we have in mind, which will ultimately lead us to identify crucial gaps that may necessitate further investigation or intervention. Thereafter, we can meaningfully proceed to the next stages of developing and evaluating health interventions.

\section{References}

1. Ng CJ. We need a research plan. Malays Fam Physician. 2020;15(3):1.

2. Teh LC, Muninathan P, MP Choy, et al. Attitudes, barriers and facilitators to the conduct of research in government hospitals: A cross-sectional study among specialists in government hospitals, northern states of Malaysia. Med J Malaysia. 2017;72(1):26-31.
3. Dans AL, Dans LF, Silvestre MAA, editors. Painless evidence-based medicine. Chichester, England: John Wiley \& Sons; 2016.
4. Godlee F. Editorial: Applying research evidence to individual patients: Evidence based care reports will help. BMJ. 1998;316:1621-2. 